International Journal of Medical Sciences

ISSN 1449-1907 www.medsci.org 2006 3(1):11-13

Research paper

\title{
Postoperative pain scores and analgesic requirements after thyroid surgery: Comparison of three intraoperative opioid regimens
}

\author{
C. Motamed, J.C. Merle, L. Yakhou, X. Combes, J. Vodinh, C. Kouyoumoudjian, P. Duvaldestin \\ Service d'Anesthesie Réanimation Hospital Henri Mondor, Créteil APHP, Université Paris 12, FRANCE \\ Corresponding address: Dr Cyrus Motamed, Service d' Anesthesie, Institut Gustave Roussy, Rue Camille Desmoulins. Villejuif, \\ France. Email: motamed@igr.fr
}

Received: 2005.08.19; Accepted: 2005.11.28; Published: 2006.01.01

Purpose: This study was designed to compare the effect on postoperative pain, opioid consumption and the length of stay in postoperative care unit (PACU) after three different intraoperative analgesic regimens in thyroid surgery. Methods: Seventy five patients were enrolled into the study and assigned to one of three groups, fentanyl, sufentanil or remifentanil ( $\mathrm{n}=25$ for each group). Before the end of surgery, paracetamol 1 gr and nefopam $20 \mathrm{mg}$ was also administered in all patients. Pain scores, opioid demand and the length of stay in PACU were assessed in a blind manner. Results: Post operative pain scores were significantly lower in the fentanyl and sufentanil groups compared to remifentanil group $(55 \pm 15$, and $60 \pm 10$ versus $78 \pm 12, \mathrm{P}<0.05)$. Patients in the remifentanil group stayed longer in the PACU $108 \pm 37$ min versus $78 \pm 31$ and $73 \pm 25 \mathrm{~min},(\mathrm{P}<0.05)$. Conclusion: After remifentanil based analgesia, anticipation of postoperative pain with opioid analgesic appears mandatory even for surgery rated as being moderately painful, otherwise longer opioid titration due to higher pain scores might delay discharge time.

Key words: postoperative analgesia, morphine titration, thyroid surgery

\section{INTRODUCTION}

Post operative pain after thyroid surgery might be important especially in the early postoperative hours. Different techniques or medications including nonsteroidal anti-inflammatory drugs (NSAID) in combination with propacetamol, oral morphine, buprenorphine, local anesthetics using either infiltration or combined superficial and deep cervical blockade have been assessed and/or suggested [1-4]. We hypothesized that the choice of opioid analgesic regimen might influence the immediate postoperative period especially the pain scores and the length of stay in the post anesthetic care unit (PACU). In this open randomized study, we compared postoperative pain management using three different intraoperative opioid analgesic regimens.

\section{METHODS}

After the approval of institutional review board of hospital Henri-Mondor and the informed consent obtained from each patient, seventy five adults ASA I-II scheduled for elective total thyroidectomy for multinodular goiter were enrolled into the study. All patients were euthyroid before surgery which was performed by the same surgeon. Patients were excluded if they had any analgesic medication or corticosteroid drug prior surgery. They were instructed the day before surgery about the study design and to express their pain in a $101 \mathrm{~mm}$ Visual Analogic Scale, $[0=$ no pain, $100=$ maximum pain $]$ (VAS). Premedication was hydroxyzine $50 \mathrm{mg} 1$ hour before surgery.

Patients were assigned according to a computerized list of random numbers into 3 groups. Group Fentanyl $(n=25)$, group Sufentanil $(n=25)$ and group Remifentanil $(n=25)$. All patients had general anesthesia induced with propofol, $2.5-4 \mathrm{mg} / \mathrm{kg}$. Tracheal intubation was performed without muscle relaxant, and anesthesia was maintained with isoflurane (end tidal 0.7-1\%) and N2O/O2(50/50).
Analgesia was started with a bolus fentanyl $2-3 \mu \mathrm{g} / \mathrm{kg}$, sufentanil $0.2-0.3 \mu \mathrm{g} / \mathrm{kg}$, or remifentanil $0.4-5 \mu \mathrm{g} / \mathrm{kg}$ and maintained with boluses of fentanyl $0.5-1 \mu \mathrm{g} / \mathrm{kg}$, sufentanil $0.08-0.15 \mu \mathrm{g} / \mathrm{kg}$, until the end of the dissection of the first thyroid lobe while the infusion of remifentanil 0.05-0.25 $\mu \mathrm{g} / \mathrm{kg} / \mathrm{min}$ was maintained until the last surgical stitch.

If surgery had to be prolonged because of cancer or other surgical complication, the patient was excluded from the study and additional patients were enrolled.

After the dissection of the first thyroid lobe, all patients received $1 \mathrm{~g}$ of paracetamol and $20 \mathrm{mg}$ nefopam IV as part of multimodal prevention of postoperative pain. Except for the remifentanil group, no other analgesic was injected until extubation. Patients were extubated in the operating room.

In the operating room

The following parameters were recorded: Duration of anesthesia, duration of surgery, intraoperative anesthetics requirements and time to extubation defined as the delay between the end of surgery and extubation.

\section{In the $P A C U$}

Clinical monitoring consisted of continuous EKG, pulse oximetry non invasive intermittent blood pressure measurements, respiratory frequency, pulse oximetry and temperature measurement with an infrared tympanic thermometer. The PACU staff and nurses were not aware of the analgesic assignment.

The following regimen of morphine titration was established in the PACU. Upon extubation patients were asked to rate pain in a $(0-100 \mathrm{~mm})$ VAS, when the VAS score was greater than $40 \mathrm{~mm}$ intravenous morphine was titrated every $5 \mathrm{~min}$ in $2 \mathrm{mg}$ increments and pain was assessed every 5 min until relief (VAS< 40). The following parameters were recorded: time of extubation, first VAS pain scores, the necessity, the amount of morphine titration to reach a VAS of $<40$, the incidence of nausea and 
vomiting and sedation score $(0=$ awake, $1=$ mild, $2=$ sleepy but awakable, and $3=$ very sleepy) and the length of stay in the PACU. The latter was decided by a physician unaware of the randomisation and based by stable vital signs for at least $30 \mathrm{~min}$, VAS pain score of less than 40 , lack of surgical complication, absence of opioid related side effects (nausea and vomiting) and a core temperature above $36^{\circ} \mathrm{C}$.

\section{In the surgical ward}

Paracetamol injections were repeated systematically every 6 hours, while nefopam was repeated every 8 hours with a pain score evaluation by a nurse every 4 hours. If the VAS score was higher than 40, subcutaneous morphine 5-10 mg was injected.

Maximum postoperative pain scores, the necessity of morphine injection, the incidence of opioid related side effects (nausea and vomiting, and sedation) were noted for the first 24 postoperative hours.

\section{Statistical analysis}

The sample size was calculated to obtain a difference in the immediate postoperative pain scores of $30 \mathrm{~mm}$ and a standard deviation of 15 , with a power of 0.8 , a $P$ value of 0.05 was considered to be significant. Data were analyzed using Jandel Sigmastat statistical software (San Rafael, Ca, USA). ANOVA and Kruskall Wallis Rank sum test were used for comparison between groups depending on distribution.

\section{RESULTS}

Six patients were withdrawn from the study: 4 out of 6 for prolonged surgery for the presence of cancer, and 2 out of 6 for surgical hematoma and drainage. All other patients completed the study. Demographic characteristics and intraoperative anesthetics requirements are represented in Table 1 and 2.

Table 1. Patients characteristics

\begin{tabular}{|c|c|c|c|}
\hline & $\begin{array}{c}\text { Group } \\
\text { Sufentanil } \\
(\mathrm{n}=24)\end{array}$ & $\begin{array}{c}\text { Group } \\
\text { Fentanyl } \\
(\mathrm{n}=24)\end{array}$ & $\begin{array}{c}\text { Group } \\
\text { Remifentanil } \\
(\mathrm{n}=21)\end{array}$ \\
\hline Weight $(\mathrm{kg})$ & $70 \pm 16$ & $68 \pm 18$ & $71 \pm 18$ \\
\hline Height $(\mathrm{cm})$ & $168 \pm 7$ & $170 \pm 9$ & $168 \pm 8$ \\
\hline Age $(\mathrm{yr})$ & $44 \pm 12$ & $48 \pm 14$ & $47 \pm 13$ \\
\hline (male /female) & $9 / 15$ & $7 / 17$ & $7 / 14$ \\
\hline
\end{tabular}

Values are \pm SD as appropriate.

Extubation delays were significantly lower in the remifentanil group, $\mathrm{P}<0.05$, (Table 2 ).

The initial postoperative pain scores in the PACU were significantly lower in the sufentanil and fentanyl group compared to remifentanil group, $(P<0.05)$. The necessity and total amount of morphine titration in the PACU were significantly less in the sufentanil and fentanyl group compared to the remifentanil group, $(P<0.05)$ Table 2 .

In the surgical ward, maximum pain scores and the incidence and the amount of morphine requirements were not different between groups.

No patient had heavy sedation in either of the groups.

The incidence of nausea and vomiting was not different between groups.
Table 2. Intraoperative anesthetic and surgical characteristics, Pain scores, length of stay in the PACU, opioid demand and opioid related side effects.

\begin{tabular}{|c|c|c|c|c|}
\hline & $\begin{array}{l}\text { Group } \\
\text { Sufentanil } \\
(\mathrm{n}=24)\end{array}$ & $\begin{array}{l}\text { Group } \\
\text { Fentanyl } \\
(\mathrm{n}=24)\end{array}$ & $\begin{array}{c}\text { Group } \\
\text { Remifentanil } \\
(\mathrm{n}=21)\end{array}$ & significance \\
\hline $\begin{array}{l}\text { Sufentanil/Fentanyl/ } \\
\text { Remifentanil }(\mu \mathrm{g})\end{array}$ & $25 \pm 5 /-/-$ & $\stackrel{-}{/ 260 \pm 65 /-}$ & $-/-/ 650 \pm 260$ & NA \\
\hline $\begin{array}{l}\text { Duration of surgery } \\
\text { (min) }\end{array}$ & $70 \pm 22$ & $80 \pm 23$ & $73 \pm 25$ & NS \\
\hline $\begin{array}{c}\text { Extubation delay } \\
\text { (min) }\end{array}$ & $10 \pm 6$ & $12 \pm 5$ & $4 \pm 3^{*}$ & $\mathrm{P}<0.05$ \\
\hline $\begin{array}{l}\text { VAS (mm) After } \\
\text { extubation }\end{array}$ & $55 \pm 15$ & $60 \pm 10$ & $78 \pm 12^{*}$ & $\mathrm{P}<0.05$ \\
\hline Necessity of Titration & $11 / 24$ & $13 / 24$ & $21 / 21^{*}$ & $\mathrm{P}<0.05$ \\
\hline $\begin{array}{l}\text { Amount of morphine } \\
\text { in PACU (mg) }\end{array}$ & $4 \pm 3$ & $5 \pm 3$ & $10 \pm 4^{*}$ & $\mathrm{P}<0.05$ \\
\hline $\begin{array}{l}\text { Length of stay in the } \\
\text { PACU (min) }\end{array}$ & $78 \pm 31$ & $73 \pm 25$ & $108 \pm 30^{*}$ & $\mathrm{P}<0.05$ \\
\hline $\begin{array}{c}\text { Incidence of PONV } \\
(\%)\end{array}$ & $46 \%$ & $43 \%$ & $52 \%$ & NS \\
\hline Sedation $;(0 / 1 / 2 / 3)$ & $12 / 12 / 0 / 0$ & $\begin{array}{c}10 / 14 / 0 / \\
0\end{array}$ & $12 / 9 / 0 / 0$ & NS \\
\hline $\begin{array}{l}\text { Maximum } \\
\text { postoperative pain } \\
\text { scores in the ward } \\
\text { (First } 24 \text { hours) }\end{array}$ & $50 \pm 20$ & $55 \pm 23$ & $50 \pm 25$ & NS \\
\hline $\begin{array}{l}\text { Additional morphine } \\
\text { in the surgical ward } \\
\text { (First } 24 \text { hours) }\end{array}$ & $12 \%$ & $13 \%$ & $15 \%$ & NS \\
\hline
\end{tabular}

* Group remifentanil versus group fentanyl and sufentanil. (PACU = post anesthetic care unit, $\mathrm{PONV}=$ postoperative nausea and vomiting, $\mathrm{VAS}=$ visual analgesic scale)

\section{DISCUSSION}

This study shows that the combination of paracetamol and nefopam alone was not sufficient to adequately control postoperative pain after thyroid surgery especially after remifentanil based analgesia and suggest the use of an opioid based analgesia in the early postoperative period. However opioid were necessary only in $1 / 3$ of patients after sufentanil and fentanyl based analgesia while almost always necessary in case of remifentanil based analgesia. The necessity of anticipation of postoperative pain in case of remifentanil analgesia is well documented [5-7]. Nevertheless it is not always clear whether this anticipation should use opioid analgesics or other agents [8-10]. In addition, we could detect a delay in discharge criteria in the remifentanil group most probably related to higher pain scores and longer necessity of titration. On the other hand delay to extubation was shorter in the remifentanil group, this might have some advantages especially when neurologic assessment is mandatory [11]. Thyroid surgery is rated as being moderately painful $[12,13]$, therefore we hypothesized that anticipation of postoperative pain with a combination of paracetamol and nefopam could adequately prevent postoperative pain and yield acceptable pain scores in all groups. However this was not the case as pain scores were significantly higher in the remifentanil groups. This difference might have several explanations, including the concept of hyperalgic activity after remifentanil based analgesia [14] but also the pharmacokinetic of fentanyl and sufentanil yielding a moderate degree of postoperative analgesia [15, 16]. Our study has some limitations including the fact the anesthetist in charge of the procedure was aware of the analgesic assignment, however since the outcome of the study was focused on immediate postoperative period we believe the results could not be affected. Postoperative pain 
after thyroid surgery might have different explanations including the skin incision, pharyngolaryngeal morbidity after intubation and neck hyperextension [17, 18]. Multiple techniques and protocols have been suggested in order to decrease postoperative pain after this type of surgery, including local anesthetic using infiltration or cervical block and multimodal analgesia using (NSAID) [1, 2, 19]. We are aware that the latter drugs are also efficient in reducing morphine consumption in this type of surgery, however the addition of a third non opioid analgesic drug in addition to paracetamol and nefopam could have made the endpoint of the study more difficult to reach. Thyroid surgery is associated with high incidence of nausea and vomiting; however the incidence of these symptoms in our group of patients was comparable to other studies [20].

In summary, when compared to fentanyl and sufentanil, the use of remifentanil was associated with a significant increase in immediate postoperative pain and the length of stay in the PACU. This study highlights the importance of anticipating postoperative pain by opioid when remifentanil is used even though when the surgery is described as yielding low to moderate level of post operative pain.

\section{Conflict of interest} exists.

The authors have declared that no conflict of interest

\section{REFERENCES}

1. Aunac S, Carlier M, Singelyn F, De Kock M. The analgesic efficacy of bilateral combined superficial and deep cervical plexus block administered before thyroid surgery under general anesthesia. Anesth Analg 2002; 95:746-50.

2. Basto ER, Waintrop C, Mourey FD, Landru JP, Eurin BG, Jacob LP. Intravenous ketoprofen in thyroid and parathyroid surgery. Anesth Analg 2001; 92:1052-7.

3. Karamanlioglu B, Arar C, Alagol A, Colak A, Gemlik I, Sut N. Preoperative oral celecoxib versus preoperative oral rofecoxib for pain relief after thyroid surgery. Eur J Anaesthesiol 2003; 20:490-5.

4. Karamanlioglu B, Turan A, Memis D, Ture M. Preoperative oral rofecoxib reduces postoperative pain and tramadol consumption in patients after abdominal hysterectomy. Anesth Analg 2004; 98:103943.

5. Albrecht S, Fechner J, Geisslinger G, et al. Postoperative pain control following remifentanil-based anaesthesia for major abdominal surgery. Anaesthesia 2000; 55:315-22.

6. Cafiero T, Di Minno RM, Sivolella G, Di Iorio C. Immediate postoperative pain management in patients undergoing major abdominal surgery after remifentanil-based anesthesia: sufentanil vs tramadol. Minerva Anestesiol 2004; 70:661-9.

7. Cafiero T, Burrelli R, Latina P, Mastronardi P. Analgesic transition after remifentanil-based anesthesia in neurosurgery. A comparison of sufentanil and tramadol. Minerva Anestesiol 2004; 70:45-52.

8. Servin F. Remifentanil: when and how to use it. Eur J Anaesthesiol Suppl 1997; 15:41-4.

9. Servin F. Remifentanil; from pharmacological properties to clinical practice. Adv Exp Med Biol 2003; 523:245-60.

10. Hachenberg T. Perioperative management with short-acting intravenous anesthetics. Anaesthesiol Reanim 2000; 25:144-50.

11. Doyle PW, Coles JP, Leary TM, Brazier P, Gupta AK. A comparison of remifentanil and fentanyl in patients undergoing carotid endarterectomy. Eur J Anaesthesiol 2001; 18:13-9.

12. Defechereux T, Meurisse M, Hamoir E, Gollogly L, Joris J, Faymonville ME. Hypnoanesthesia for endocrine cervical surgery: a statement of practice. J Altern Complement Med 1999; 5:509-20.

13. Defechereux T, Degauque C, Fumal I, et al. Hypnosedation, a new method of anesthesia for cervical endocrine surgery. Prospective randomized study. Ann Chir 2000; 125:539-46.
14. Guignard B, Bossard AE, Coste C, et al. Acute opioid tolerance: intraoperative remifentanil increases postoperative pain and morphine requirement. Anesthesiology 2000; 93:409-17.

15. Shafer SL, Varvel JR, Aziz N, Scott JC. Pharmacokinetics of fentanyl administered by computer-controlled infusion pump. Anesthesiology 1990; 73:1091-102.

16. Shafer SL, Varvel JR. Pharmacokinetics, pharmacodynamics, and rational opioid selection. Anesthesiology 1991; 74:53-63.

17. Kloub R. Sore throat following tracheal intubation. Middle East J Anesthesiol 2001; 16:29-40.

18. McHardy FE, Chung F. Postoperative sore throat: cause, prevention and treatment. Anaesthesia 1999; 54:444-53.

19. Vach B, Kurzova A, Malek J, Fanta J, Pachl J. Infiltration of local anesthetics into the thyroid gland capsule for surgery and the postoperative period. Rozhl Chir 2002; 81:519-22.

20. Sonner JM, Hynson JM, Clark O, Katz JA. Nausea and vomiting following thyroid and parathyroid surgery. J Clin Anesth 1997; 9:398402. 